\title{
Effects of novel antidiabetes agents on apoptotic processes in diabetes and malignancy: Implications for lowering tissue damage
}

\author{
Habib Yaribeygi ${ }^{1 *}$, Fadel Lhaf ${ }^{2}$, Thozhukat Sathyapalan ${ }^{2}$, Amirhossein Sahebkar ${ }^{3,4,5^{*}}$ \\ ${ }^{1}$ Chronic Kidney Disease Research Center, Shahid Beheshti University of Medical \\ Sciences, Tehran, Iran \\ ${ }^{2}$ Academic Diabetes, Endocrinology and Metabolism, Hull York Medical School, \\ University of Hull \\ ${ }^{3}$ Biotechnology Research Center, Pharmaceutical Technology Institute, Mashhad University \\ of Medical Sciences, Mashhad, Iran \\ ${ }^{4}$ Neurogenic Inflammation Research Center, Mashhad University of Medical Sciences, \\ Mashhad, \\ Iran \\ ${ }^{5}$ School of Pharmacy, Mashhad University of Medical Sciences, Mashhad,
}

lhaf, fadel

\section{*Corresponding Authors:}

Amirhossein Sahebkar, Biotechnology Research Center, Mashhad University of Medical Sciences, Mashhad 9177948564, Iran. Tel: +985138002299; Fax: +985138002287; E-mail:

sahebkara@mums.ac.ir; amir_saheb2000@yahoo.com

Habib Yaribeygi,

Chronic Kidney Disease Research Center, Shahid Beheshti University of Medical Sciences, Tehran, Iran, Tel: $\underline{+98-2181263619 .}$.

Running Title: Novel antidiabetic agents and apoptosis

Manuscript word count $-2491 \quad$ Abstract word count -126

O2019, Elsevier. This manuscript version is made available under the CC-BY-NC-ND 4.0 license http://creativecommons.org/licenses/by-nc-nd/4.0/ 


\begin{abstract}
Apoptosis is a complicated process that involves activation of a series of intracellular signaling. Tissue injuries from diabetes mellitus mostly occur as a consequence of higher rate of apoptosis process due to activation of a series of molecular mechanisms. Several classes of antihyperglycaemic agents have been developed which could potentially modulate the apoptotic process resulting in fewer tissue damages. Novel types of anti-hyperglycaemic medications such as sodium glucose cotransporters-2 inhibitors, glucagon like peptide-1 receptor agonists and dipeptidyl peptidase 4 inhibitors have shown to provide potent anti-hyperglycaemic effects, but their influences on diabetes-induced apoptotic injuries is largely unknown. Therefore, in the current study, we reviewed the published data about the possible effects of these anti-hyperglycaemic agents on apoptosis in diabetic milieu as well as in cancer cells.
\end{abstract}

Keywords: SGLT2 inhibitor, GLP-1 Receptor Agonist, DPP-4 inhibitor, Oxidative stress, Apoptosis, Diabetes Mellitus, Caspase, Cancer 


\section{Introduction}

The global prevalence of diabetes mellitus (DM) is increasing exponentially (Mayer-Davis et al. , 2017). Diabetes is responsible for multitude cases of hospitalization, disability and death worldwide (Cavender et al. , 2015). There is a growing evidence that DM induces several pathophysiologic molecular pathways such as oxidative stress, inflammation, fibrosis and apoptosis in various tissues triggering irreversible tissue damage (Yaribeygi et al. , 2019a, Yaribeygi et al. , 2018c, Yaribeygi et al. , 2018d). Different classes of anti-hyperglycaemic medications have been developed to normalize blood glucose and prevent of diabetes-related complications (Association, 2016, Yaribeygi et al. , 2019b). If these anti-hyperglycaemic agents could modulate underlying molecular mechanisms of diabetic complications, there is a potential to develop novel potent therapeutic approaches against hyperglycemia-induced tissue injuries (Yaribeygi et al. , 2018b, Yaribeygi et al. , 2019c). Since apoptotic processes have major roles in various types of diabetes dependent tissue damages, in the current study we shed light on possible anti-apoptotic properties of novel antidiabetic medications such as sodium glucose cotransporters-2 inhibitors (SGLT2i), glucagon like peptide-1 receptor agonists (GLP1RA) and dipeptidyl peptidase 4 inhibitors (DPP-4i) in the diabetic milieu and potentially in cancer.

\section{Apoptosis}

Apoptosis is a distinct feature of programmed cell death which physiologically occurs during many biologic processes such as cell growth, cell differentiation, cell migration, embryonic development, cell turn over, atrophy and cell death (Elmore, 2007, Wang, 2015). In this phenomena, several forms of destruction such as cell shrinking, plasma blebbing, chromatin condensation, nuclear fragmentation, DNA fragmentation and mRNA decay occurs resulting in cell death (Elmore, 2007, Hengartner, 2000). It has well established that apoptosis is a highly 
regulated process and is influenced by various stimuli such as free radicals, nutrient deprivation, hypoxia, heat, glucocorticoids, inflammatory mediators, toxins, hyperglycemia, abnormal concentration of ions, invader pathogens, ER (endoplasmic reticulum) stress, radiation, higher concentration of free fatty acids and stress. (Hengartner, 2000, Strasser et al. , 2000).

In addition, various biologic agents such as Fas receptors (apoptosis antigen-1), t-Bid (a membrane-targeted death ligand), TLRs (toll like receptors), death receptors, Bax/Bcl2 ratio, TRAIL (tumor necrosis factor related apoptosis inducing ligand) receptors, and p53 protein have potent regulatory effects on onset and progression of apoptotic pathways (Barth et al. , 2003, Hengartner, 2000, Strasser et al., 2000) suggesting apoptosis is a very complicated but highly regulated energy-consuming cascade of molecular events (Elmore, 2007, Hengartner, 2000). Both apoptosis progression and inhibition are important since in some condition such as cancer, apoptosis progression helps to prevent metastasis, but in some other milieu such as diabetes kidney disease, we want to suppress apoptosis to lower tissue injuries (Hengartner, 2000, Lowe and Lin, 2000).

Apoptosis process is commonly triggered via at least two different molecular pathways viz. intrinsic and extrinsic pathways (Hengartner, 2000). While intrinsic pathway is mostly initiated by mitochondria, extrinsic pathway is activated by binding of a apoptotic stimuli to specific plasma membrane receptors leading to complicated intracellular signalings (Elmore, 2007, Hengartner, 2000). Also, another distinct novel pathway of apoptosis activation has been identified as perforin/granzyme pathway which is activated by binding cytotoxic T lymphocyte cells to specific cellular transmembrane receptors namely perforin and by activating granzyme A or granzyme B which are serine proteases (Elmore, 2007, Trapani and Smyth, 2002, Vermijlen et al. , 2002). In addition, it promotes the activation of different agents such as caspase, proteases and a series of adaptor proteins (Elmore, 2007, Vermijlen et al., 2002). 


\section{Apoptosis Process and Diabetes-Induced Tissue Injuries}

In addition to the cellular growth and developmental process, apoptosis also has major roles in many forms of tissue injuries as well as in diabetes complications (Aufiero et al. , 2006, Krijnen et al. , 2009). Distinct forms of diabetes-induced cellular damages such as pancreatic beta cell dysfunction, renal glomerular sclerosis, endothelial cell dysfunction, peripheral neuropathy, diabetes dependent memory deficit and vascular incompliance are strongly related to higher levels of un-controlled pathogenic apoptosis which is stimulated by chronic hyperglycemia in patients with diabetes (Anuradha et al. , 2014, Sima and Li, 2006, Srinivasan et al. , 2000, Verzola et al. , 2007). Therefore, diabetes-induced apoptosis a has major role in the pathophysiology of many features of diabetes complications such as diabetic nephropathy, diabetic retinopathy, diabetic neuropathy and cardiovascular disorders (Allen et al. , 2005, Krijnen et al., 2009).

Higher concentrations of circulatory glucose can be a potent inducer for apoptosis by activating the aforementioned proapoptotic agents and dysregulation of normal physiologic cell cycle toward death (Figure 1) (Allen et al., 2005, Barth et al., 2003, Krijnen et al., 2009). Also, diabetes indirectly increases apoptosis-related cellular damages by potentiating other stimuli of apoptosis such as oxidative stress and inflammation (Allen et al., 2005). Consequently, apoptotic process results in higher rate of tissue dysfunction in patients with diabetes with respect to diabetes complications such as diabetic kidney disease (Barth et al., 2003, Krijnen et al., 2009).

\section{Novel Antidiabetic Agents of SGLT2i, GLP-1RA and DPP-4i at a Glance}

SGLT2 inhibitors (SGLT2i) are a newly diagnosed family of anti-diabetic medications which decrease circulatory glucose by inhibition of renal tubular glucose reabsorption and induction of urinary glucose excretion (Davidson and Kuritzky, 2014, Yaribeygi et al. , 2018a). These 
antihyperglycaemic agents act completely independent of insulin secretion and are only correlated to circulating glucose. They also does not have the risk of hypoglycaemia (Chao, 2014). After the discovery of was the first SGLT2i phlorizin, other agents in this class have been developed which reduce blood glucose nearer to the level of the glucose reabsorption capacity of nephrons (Chao, 2014, Chao and Henry, 2010, Clar et al. , 2012, Makarova et al. , 2015). They also have other anti-hyperglycaemic actions such as inhibition of gluconeogenesis, improvement of insulin sensitivity, increasing the glucagon response and stimulating insulin secretion from the beta cells of pancreas (Ferrannini et al., 2014, Han et al. , 2008, Kern et al. ,2016, Wilding et al. , 2014).

GLP-1 RA is another class of recently introduced anti-hyperglycaemic agents that was first approved by FDA in 2010 for the management of diabetes (Yaribeygi et al., 2018b). They act as a potent agonist for GLP-1 receptors and thereby mimic the effects of incretin hormones. They are a family of metabolic hormones secreted by the gastro-intestinal tract that reduce postprandial circulatory glucose via inhibition of glucagon secretion from pancreatic $\alpha$-cells and stimulating insulin release from $\beta$-cell in a blood glucose dependent manner (Baggio and Drucker, 2007, Drucker and Nauck, 2006, Islam, 2016, Meier, 2012). They can also provide additional anti-hyperglycaemic effects by delaying the gastric emptying, appetite suppression, reduction in nutrient absorption and improvement of lipid metabolism (Ding et al. , 2006, Meier, 2012, Scott and Moran, 2007). These drugs act by biding to GLP-1R that are predominantly expressed in islets' $\beta$-cells (Baggio and Drucker, 2007).

DPP-4 inhibitors (DPP-4i) is the other novel class of antidiabetes agents which produces antihyperglycemic effect by inhibiting GLP-1 inactivation and thereby raising the active levels of GLP-1 (Ahren, 2007, Association, 2018). After post-translational processes of pre-glucagon (PG) peptides in the intestinal cells, at least four distinct forms of PG released which are all inactivated by DPP-4 enzyme via removing the two amino acids from their N- 
terminal residue (Brubaker, 2006). As a result, the DPP-4i have similar but less potent antihyperglycemic effects to GLP-1 agonists, although they may show some differences on weight loss and the risk of adverse effects (Association, 2018).

\section{SGLT2i and Apoptosis}

In recent years, some studies have focused on the possible effects of SGLT2 inhibition on apoptosis process (Nipon Chattipakorn, 2018, Sa-nguanmoo et al. , 2017). Their findings strongly suggested that these agents could influence apoptosis by inducing as well as suppressing apoptosis in differing conditions (tables 1 and 2) (Sa-nguanmoo et al., 2017, Satirapoj, 2017). While empagliflozin therapy can inhibit beta cell apoptosis in pancreatic cells, ipragliflozin induces apoptosis in MCF-7 cells (human breast cancer cell line) (Cheng et al. , 2016, KOMATSU et al. , 2018). These findings suggests that SGLT2 inhibition results in progression or inhibition of apoptosis in different disease states (Cheng et al., 2016, KOMATSU et al., 2018). In fact, either progression or inhibition of apoptosis are potential therapeutic targets in distinct conditions such as diabetes complications or cancer (Hengartner, 2000).

\section{$\underline{\text { SGLT2i and apoptosis Inhibition }}$}

Cheng et al in 2016 demonstrated that empagliflozin inhibited beta cells apoptosis via ameliorating glucotoxicity-induced oxidative stress (Cheng et al., 2016). They suggested that hyperglycemia-dependent oxidative stress has upstream effect on apoptosis and thereby, lowering blood glucose by SGLT2 inhibition, reduces apoptosis and increases beta cell mass in diabetic animals (Cheng et al., 2016). Nipon et al in 2018 established that SGLT2 inhibition using dapagliflozin prevent obesity-induced apoptosis by attenuation of oxidative stress, ER stress and obesity in renal tissues of diabetic rats (Nipon Chattipakorn, 2018). 
Sa-nguanmoo et al in 2017 have shown that dapagliflozin can exert neuroprotective effects by preventing inflammation and oxidative stress in brain tissue leading to amelioration of apoptosis process and improving cognitive function in obesity-induced insulin resistant rats (Sa-nguanmoo et al., 2017). Another study demonstrates that dapagliflozin attenuated apoptotic processes by reducing renin-angiotensin system (RAS) activity and lowering oxidative stress in renal tissue of diabetic animals (Shin et al. , 2016). Moreover, Lee and coworkers in 2018 demonstrated that SGLT2 inhibition by empagliflozin protected renal proximal tubular cells from apoptosis by reducing intra-renal lipotoxicity in HK2 cells treated with high glucose concentration (Lee et al. , 2018). They also found that empagliflozin upregulated the Bcl-2 and downregulated the t-Bid, Bax and cytochrome-C protein expression and inactivated the caspase-3, 8 and 9 in kidney tissues (Lee et al., 2018). Moreover, Staels et al in 2017 suggested the anti-apoptotic potentials of SGLT2i in cardiovascular network as cardioprotective effects of these antidiabetic agents (Staels, 2017). These data (Table 1) strongly suggest that SGLT2 inhibition ameliorates apoptosis mainly via suppressing oxidative stress in the diabetic milieu (Okauchi et al. , 2016).

\section{$\underline{\text { SGLT2i and Apoptosis Progression }}$}

Some evidences indicated that SGLT2 inhibition can induce apoptosis process in conditions such as cancer (KOMATSU et al., 2018). Komatsu and colleagues in 2018 found that ipragliflozin markedly increases apoptotic processes in breast cancer cells (KOMATSU et al., 2018). Also, Kuang and coworkers in 2017 demonstrated that dapagliflozin induces apoptotic events and reduces tumor volume in human renal cancer cells (Kuang et al. , 2017). SGLT2 inhibition with canagliflozin induces remarkable apoptosis processes in human hepatocellular carcinoma cells (Kaji et al. , 2018). These evidences imply that SGLT2i therapy in cancer cells promotes apoptosis unlike diabetic milieu in which SGLT2i suppress apoptosis (Table 2) (Han et al. , 2018, Maeda et al. , 2013). These data strongly suggests that SGLT2i have beneficial 
effects on apoptotic processes and can induce them in such conditions as cancer, but inhibit them in pathologic conditions such as diabetic kidney diseases (Ishibashi et al. , 2016, Kaji et al., 2018, Maeda et al., 2013, Nair and Rupasinghe, 2014).

\section{GLP-1RA \& DPP-4i and Apoptosis}

Induction of GLP-1 receptors by related agonists/medications may modulates apoptosis process (Sa-nguanmoo et al., 2017, Urusova et al. , 2004) (Table 3). Addition of GLP-1 peptide in human cultured beta cells preserved its mass and inhibited apoptosis by caspase-3 downregulation and the up-regulation of bcl-2 (Farilla et al. , 2003). Extedinn-4, one of the GLP-1 peptides, reduces beta cells' susceptibility to apoptosis and induces islets' neogenesis by attenuating inflammatory cytokines as IL- $1 \beta$ (interleukin $1 \beta)$, TNF- $\alpha$ (tumor necrosis factor $\alpha$ ), and interferon- $\gamma$ in diabetic animals ( $\mathrm{Li}$ et al. , 2003). They can also ameliorate beta cell apoptosis and maintain islets mass (Urusova et al., 2004). GLP-1 addition to human cultured islets inhibited apoptosis by induction of IGF-1 (insulin like growth factor-1) receptor expression and attenuating inflammatory mediators leading to activating specific G-protein dependent receptors; cAMP activation and beta cells' regeneration (Cornu et al. , 2008). Vildagliptin (DPP-4i) therapy in obese rats improves brain function via attenuating neuronal apoptosis, although its effects was weaker compared to dapagliflozin (Sa-nguanmoo et al., 2017).

Reviewed data suggest that GLP-1R activation can suppresses apoptosis and reduces tissue injuries by different mechanisms to SGLT2i. These includes various molecular mechanisms such as IGF-1 activation, caspases inactivation, PKB, PKA, PI3K and SIRT1 signaling pathways and improvement of mitochondrial function in the diabetes milieu (Chang et al. , 2016, Cornu et al., 2008, Farilla et al., 2003, Li et al. , 2005, Sa-nguanmoo et al., 2017, Son et al. , 2018). Similar findings have been observed on the effect of DPP-4i effects on 
apoptosis (Nagamine et al. , 2017, Shirakawa et al. , 2011). Evidence indicates that using DPP4i in diabetic milieu can reduces apoptotic processes by different molecular mechanisms such as down-regulating proapoptotic agents and making cytoprotective effects (Nagamine et al., 2017, Shirakawa et al., 2011).

In contrast, in cancer cells; there is growing evidence that these agents could protect tissues by apoptosis induction and have anti-cancer effects. One of the DPP-4i, sitagliptin, markedly promotes apoptosis process and have anti-cancer effects in human cultured colon cancer cells (Amritha et al. , 2015). DPP-4 expression is also correlated to cancer progression suggesting that DPP-4i may have a modulatory effects on these cells by induction of apoptosis (Larrinaga et al. , 2015). Exenatide and liraglutide (GLP-1RA) both induce apoptosis by raising Bax/Bcl2 ratio and activating p38 molecular mechanisms in human prostate cancer cell lines (Li et al.

, 2017) (table 4). However, some evidences are contrary to these findings (Koehler and Drucker, 2006). Koehler et al in 2006 found that treatment by extendin-4 did not modify apoptosis in human pancreatic carcinoma cells and was not effective in lowering tumor size (Koehler and Drucker, 2006). Exendin-4, another GLP-1RA was also unable to modify tumor size in prostatic cancer cells (Wenjing et al. , 2017).

\section{Conclusion}

Beyond physiologic roles, apoptosis has a major involvement in tissue injuries induced by pathologic conditions such as diabetes mellitus and cancer. Many forms of cellular injuries in diabetes related complications are a result of higher rate of uncontrolled apoptosis under influences of a varied stimuli including glucotoxicity, inflammatory cytokines and free radicals. In this milieu, SGLT2i can reduce tissue injuries by lowering glucotoxicity, lipotoxicity, oxidative stress, inflammatory responses and ER stress leading to fewer rate of apoptosis. There is a growing evidence that SGLT2i agents can potentially suppress apoptosis 
events in diabetic milieu. In contrast, in malignant cells, SGLT2 inhibition induces apoptosis processes; there by potentially reducing tumor size. They can potentially stimulate apoptosis by different molecular mechanisms such as up-regulating the BCL2 and modulating BAX/BCL2 ratio, activation of caspases, reducing intracellular ATP level, induction of mitochondrial dysfunction and exerting arrest in cell cycle in malignant tissues. Our study shows that SGLT2 inhibition has remarkable effects on apoptosis and if modulated towards therapeutic targets; they are likely to induce apoptosis in cancer cells, but inhibit it in diabetic milieu. These findings suggest new therapeutic potential for the management of tissue injuries in either patients with diabetes or with cancer; especially hepatocellular and colon cancers.

Moreover, induction of GLP-1 receptors by anti-hyperglycaemic agents such as GLP1RA or DPP-4i have potent influences on apoptotic processes. Emerging evidence suggests that GLP-1R induction markedly reduces tissue damages by suppressing apoptotic pathways. This could be potentially mediated through molecular mechanisms such as down-regulating proapoptotic agents such as caspase-3, improving mitochondrial function, ameliorating inflammatory mediators as IL- $1 \beta$, TNF- $\alpha$, and IF- $\gamma$, attenuating oxidative stress, by several intracellular signalings as Akt, PKA, PI3K, cAMP, and ERK1/2 dependent signaling pathways, bcl-2, SIRT1, $\alpha$-Klotho and IGF-1 receptor up-regulation, beta cells' regeneration and by making cytoprotective effects in diabetic milieu. Similarly, they might induce apoptotic death in cancer cells. There is emerging evidence to imply that GLP-1R induction induces apoptosis events by different molecular pathways such as raising Bax/Bcl-2 ratio and activating p380induced apoptosis as well as through signaling pathways as ERK-MAPK and MAPK dependent signaling. Conversely, some data suggest that they are unable to modulate apoptotic pathways in carcinoma cells.

In conclusion, based on the reviewed data, both SGLT2 inhibition and GLP-1R activation have inhibitory effects on apoptotic events and reduce tissue injuries in diabetes 
related complications thereby in addition to their anti-hyperglycaemic effects, they can be considered as anti-apoptotic agents. Also, SGLT2i are more likely to be potent than GLP-RA and DPP-4i for apoptosis induction in cancer cells and can decline tumor size by enhancing cellular death in distinct types of cancers.

\section{Acknowledgment}

The authors are thankful to the Clinical Research and Development Unit of the Baqiyatallah Hospital (Tehran, Iran).

\section{Conflict of Interests}

The authors clearly declare that have no conflict of interest in this study. 
1. Mayer-Davis, E.J., et al., Incidence trends of type 1 and type 2 diabetes among youths, 20022012. New England Journal of Medicine, 2017. 376(15): p. 1419-1429.

2. Cavender, M.A., et al., Impact of diabetes mellitus on hospitalization for heart failure, cardiovascular events, and death: outcomes at 4 years from the Reduction of Atherothrombosis for Continued Health (REACH) registry. Circulation, 2015. 132(10): p. 923931.

3. Yaribeygi, H., et al., Fenofibrate improves renal function by amelioration of NOX-4, IL-18, and p53 expression in an experimental model of diabetic nephropathy. Journal of cellular biochemistry, 2018.

4. Yaribeygi, H., S.L. Atkin, and A. Sahebkar, A review of the molecular mechanisms of hyperglycemia-induced free radical generation leading to oxidative stress. Journal of cellular physiology, 2019. 234(2): p. 1300-1312.

5. Yaribeygi, H., et al., Effects of atorvastatin on myocardial oxidative and nitrosative stress in diabetic rats. Comparative Clinical Pathology, 2018. 27(3): p. 691-697.

6. Yaribeygi, H., et al., Sodium-glucose cotransporter 2 inhibitors and inflammation in chronic kidney disease: Possible molecular pathways. Journal of cellular physiology, 2019. 234(1): p. 223-230.

7. Association, A.D., Standards of medical care in diabetes-2016 abridged for primary care providers. Clinical diabetes: a publication of the American Diabetes Association, 2016. 34(1): p. 3.

8. Yaribeygi, H., et al., A review of the anti-inflammatory properties of antidiabetic agents providing protective effects against vascular complications in diabetes. Journal of cellular physiology, 2018.

9. Yaribeygi, H., et al., Antioxidative potential of antidiabetic agents: A possible protective mechanism against vascular complications in diabetic patients. Journal of cellular physiology, 2019. 234(3): p. 2436-2446.

10. Elmore, S., Apoptosis: a review of programmed cell death. Toxicologic pathology, 2007. 35(4): p. 495-516.

11. Wang, K., Molecular mechanisms of hepatic apoptosis. Cell death \& disease, 2015. 5(1): p. e996.

12. Hengartner, M.O., The biochemistry of apoptosis. Nature, 2000. 407(6805): p. 770.

13. Strasser, A., L. O'Connor, and V.M. Dixit, Apoptosis signaling. Annual review of biochemistry, 2000. 69(1): p. 217-245.

14. Barth, S., A. Engert, and M. Stocker, Apoptotic agents. 2003, Google Patents.

15. Lowe, S.W. and A.W. Lin, Apoptosis in cancer. Carcinogenesis, 2000. 21(3): p. 485-495.

16. Trapani, J.A. and M.J. Smyth, Functional significance of the perforin/granzyme cell death pathway. Nature Reviews Immunology, 2002. 2(10): p. 735.

17. Vermijlen, D., et al., Hepatic natural killer cells exclusively kill splenic/blood natural killerresistant tumor cells by the perforin/granzyme pathway. Journal of leukocyte biology, 2002. 72(4): p. 668-676.

18. Aufiero, B.M., et al., Apoptosis in Tissue Injury, in Forensic Pathology Reviews. 2006, Springer. p. 331-351.

19. Krijnen, P.A., S. Simsek, and H.W. Niessen, Apoptosis in diabetes. Apoptosis, 2009. 14(12): p. 1387.

20. Sima, A.A. and Z.-g. Li, Diabetes and Alzheimer's disease-is there a connection? The Review of Diabetic Studies, 2006. 3(4): p. 161.

21. Srinivasan, S., M. Stevens, and J.W. Wiley, Diabetic peripheral neuropathy: evidence for apoptosis and associated mitochondrial dysfunction. Diabetes, 2000. 49(11): p. 1932-1938.

22. Anuradha, R., et al., Apoptosis of beta cells in diabetes mellitus. DNA and cell biology, 2014. 33(11): p. 743-748. 
23. Verzola, D., et al., Apoptosis in the kidneys of patients with type II diabetic nephropathy. Kidney international, 2007. 72(10): p. 1262-1272.

24. Allen, D.A., M.M. Yaqoob, and S.M. Harwood, Mechanisms of high glucose-induced apoptosis and its relationship to diabetic complications. The Journal of nutritional biochemistry, 2005. 16(12): p. 705-713.

25. Yaribeygi, H., et al., Sodium-glucose cotransporter inhibitors and oxidative stress: An update. Journal of cellular physiology, 2018.

26. Davidson, J.A. and L. Kuritzky, Sodium glucose co-transporter 2 inhibitors and their mechanism for improving glycemia in patients with type 2 diabetes. Postgraduate medicine, 2014. 126(6): p. 33-48.

27. Chao, E.C., SGLT-2 inhibitors: a new mechanism for glycemic control. Clinical Diabetes, 2014. 32(1): p. 4-11.

28. Makarova, E., et al., Acute anti-hyperglycaemic effects of an unripe apple preparation containing phlorizin in healthy volunteers: a preliminary study. Journal of the Science of Food and Agriculture, 2015. 95(3): p. 560-568.

29. Chao, E.C. and R.R. Henry, SGLT2 inhibition-a novel strategy for diabetes treatment. Nature Reviews Drug Discovery, 2010. 9(7): p. 551.

30. Clar, C., J.A. Gill, and N. Waugh, Systematic review of SGLT2 receptor inhibitors in dual or triple therapy in type 2 diabetes. BMJ open, 2012. 2(5): p. e001007.

31. Kern, M., et al., The SGLT2 inhibitor empagliflozin improves insulin sensitivity in $\mathrm{db} / \mathrm{db}$ mice both as monotherapy and in combination with linagliptin. Metabolism-Clinical and Experimental, 2016. 65(2): p. 114-123.

32. Han, S., et al., Dapagliflozin, a selective SGLT2 inhibitor, improves glucose homeostasis in normal and diabetic rats. Diabetes, 2008. 57(6): p. 1723-1729.

33. Wilding, J., et al., Dapagliflozin in patients with type 2 diabetes receiving high doses of insulin: efficacy and safety over 2 years. Diabetes, Obesity and Metabolism, 2014. 16(2): p. 124-136.

34. Ferrannini, E., et al., Metabolic response to sodium-glucose cotransporter 2 inhibition in type 2 diabetic patients. The Journal of clinical investigation, 2014. 124(2): p. 499-508.

35. Drucker, D.J. and M.A. Nauck, The incretin system: glucagon-like peptide-1 receptor agonists and dipeptidyl peptidase-4 inhibitors in type 2 diabetes. The Lancet, 2006. 368(9548): p. 16961705.

36. Islam, M., Insulinotropic Effect of Herbal Drugs for Management of Diabetes Mellitus: A Congregational Approach. Biosens J, 2016. 5(142): p. 2.

37. Meier, J.J., GLP-1 receptor agonists for individualized treatment of type 2 diabetes mellitus. Nature Reviews Endocrinology, 2012. 8(12): p. 728.

38. Baggio, L.L. and D.J. Drucker, Biology of incretins: GLP-1 and GIP. Gastroenterology, 2007. 132(6): p. 2131-2157.

39. Scott, K.A. and T.H. Moran, The GLP-1 agonist exendin-4 reduces food intake in nonhuman primates through changes in meal size. American Journal of Physiology-Regulatory, Integrative and Comparative Physiology, 2007. 293(3): p. R983-R987.

40. Ding, X., et al., Exendin-4, a glucagon-like protein-1 (GLP-1) receptor agonist, reverses hepatic steatosis in ob/ob mice. Hepatology, 2006. 43(1): p. 173-181.

41. Association, A.D., 2. Classification and diagnosis of diabetes: standards of medical care in diabetes-2018. Diabetes Care, 2018. 41(Supplement 1): p. S13-S27.

42. Ahren, B., DPP-4 inhibitors. Best Practice \& Research Clinical Endocrinology \& Metabolism, 2007. 21(4): p. 517-533.

43. Brubaker, P.L., The Glucagon-Like Peptides. Annals of the New York Academy of Sciences, 2006. 1070(1): p. 10-26.

44. Nipon Chattipakorn, M., Dapagliflozin, a sodium-glucose co-transporter-2 inhibitor, slows the progression of renal complications through the suppression of renal inflammation, endoplasmic reticulum stress and apoptosis in prediabetic rats. 2018. 
45. Sa-nguanmoo, P., et al., SGLT2-inhibitor and DPP-4 inhibitor improve brain function via attenuating mitochondrial dysfunction, insulin resistance, inflammation, and apoptosis in HFD-induced obese rats. Toxicology and applied pharmacology, 2017. 333: p. 43-50.

46. Satirapoj, B., Sodium-Glucose Cotransporter 2 Inhibitors with Renoprotective Effects. Kidney Diseases, 2017. 3(1): p. 24-32.

47. KOMATSU, S., et al., SGLT2 Inhibitor Ipragliflozin Induces Breast Cancer Apoptosis via Membrane Hyperpolarization and Mitochondria Dysfunction. 2018, Am Diabetes Assoc.

48. Cheng, S.T.W., et al., The effects of empagliflozin, an SGLT2 inhibitor, on pancreatic B-cell mass and glucose homeostasis in type 1 diabetes. PloS one, 2016. 11(1): p. e0147391.

49. Shin, S.J., et al., Effect of sodium-glucose co-transporter 2 inhibitor, dapagliflozin, on renal renin-angiotensin system in an animal model of type 2 diabetes. PloS one, 2016. 11(11): p. e0165703.

50. Lee, W.-C., et al., FP416 SGLT2 INHIBITOR PROTECTED RENAL PROXIMAL TUBULAR CELLS FROM APOPTOSIS BY REDUCING INTRA-RENAL LIPOTOXICITY. Nephrology Dialysis Transplantation, 2018. 33(suppl_1): p. i175-i176.

51. Terami, N., et al., Long-term treatment with the sodium glucose cotransporter 2 inhibitor, dapagliflozin, ameliorates glucose homeostasis and diabetic nephropathy in $\mathrm{db} / \mathrm{db}$ mice. PloS one, 2014. 9(6): p. e100777.

52. Hatanaka, T., et al., Inhibition of SGLT2 alleviates diabetic nephropathy by suppressing high glucose-induced oxidative stress in type 1 diabetic mice. Pharmacology research \& perspectives, 2016. 4(4).

53. Okauchi, S., et al., Protective effects of SGLT2 inhibitor luseogliflozin on pancreatic B-cells in obese type 2 diabetic $d b / d b$ mice. Biochemical and biophysical research communications, 2016. 470(3): p. 772-782.

54. Ishibashi, Y., T. Matsui, and S. Yamagishi, Tofogliflozin, a highly selective inhibitor of SGLT2 blocks proinflammatory and proapoptotic effects of glucose overload on proximal tubular cells partly by suppressing oxidative stress generation. Hormone and Metabolic Research, 2016. 48(03): p. 191-195.

55. Maeda, S., et al., Sodium-glucose cotransporter 2-mediated oxidative stress augments advanced glycation end products-induced tubular cell apoptosis. Diabetes/metabolism research and reviews, 2013. 29(5): p. 406-412.

56. Han, E., et al., Combining SGLT2 inhibition with a thiazolidinedione additively attenuate the very early phase of diabetic nephropathy progression in type 2 diabetes mellitus. Frontiers in endocrinology, 2018. 9.

57. Staels, B., Cardiovascular protection by sodium glucose cotransporter 2 inhibitors: potential mechanisms. The American journal of cardiology, 2017. 120(1): p. S28-S36.

58. Kuang, H., et al., Therapeutic effect of sodium glucose co-transporter 2 inhibitor dapagliflozin on renal cell carcinoma. Medical science monitor: international medical journal of experimental and clinical research, 2017. 23: p. 3737.

59. Kaji, K., et al., Sodium glucose cotransporter 2 inhibitor canagliflozin attenuates liver cancer cell growth and angiogenic activity by inhibiting glucose uptake. International journal of cancer, 2018. 142(8): p. 1712-1722.

60. Koehler, J.A., T. Kain, and D.J. Drucker, Glucagon-like peptide-1 receptor activation inhibits growth and augments apoptosis in murine CT26 colon cancer cells. Endocrinology, 2011. 152(9): p. 3362-3372.

61. Nair, S.V. and H.V. Rupasinghe, Fatty acid esters of phloridzin induce apoptosis of human liver cancer cells through altered gene expression. PLoS One, 2014. 9(9): p. e107149.

62. Urusova, I.A., et al., GLP-1 inhibition of pancreatic islet cell apoptosis. Trends in Endocrinology \& Metabolism, 2004. 15(1): p. 27-33.

63. Farilla, L., et al., Glucagon-like peptide 1 inhibits cell apoptosis and improves glucose responsiveness of freshly isolated human islets. Endocrinology, 2003. 144(12): p. 5149-5158. 
64. Li, Y., et al., Glucagon-like peptide-1 receptor signaling modulates 8 cell apoptosis. Journal of Biological Chemistry, 2003. 278(1): p. 471-478.

65. Cornu, M., et al. Glucagon-like peptide-1 protects beta cells against apoptosis and increases insulin secretion induced by glucose through autocrine loops depending on an insulin-like growth factor-1 receptor. in DIABETES \& METABOLISM. 2008. MASSON EDITEUR 21 STREET CAMILLE DESMOULINS, ISSY, 92789 MOULINEAUX CEDEX $9 . .$.

66. Son, D.O., et al., Combined effect of GABA and glucagon-like peptide-1 receptor agonist on cytokine-induced apoptosis in pancreatic B-cell line and isolated human islets. Journal of Diabetes, 2018.

67. Chang, T.-J., et al., Glucagon-like peptide-1 prevents methylglyoxal-induced apoptosis of beta cells through improving mitochondrial function and suppressing prolonged AMPK activation. Scientific reports, 2016. 6: p. 23403.

68. Li, L., et al., Glucagon-like peptide-1 protects beta cells from cytokine-induced apoptosis and necrosis: role of protein kinase B. Diabetologia, 2005. 48(7): p. 1339-1349.

69. Ravassa, S., et al., Antiapoptotic effects of GLP-1 in murine HL-1 cardiomyocytes. American Journal of Physiology-Heart and Circulatory Physiology, 2011. 300(4): p. H1361-H1372.

70. Nagamine, A., et al., The effects of DPP-4 inhibitor on hypoxia-induced apoptosis in human umbilical vein endothelial cells. Journal of pharmacological sciences, 2017. 133(1): p. 42-48.

71. Shirakawa, J., et al., Protective effects of a dipeptidyl peptidase-4 (DPP-4) inhibitor against increased $B$ cell apoptosis induced by dietary sucrose and linoleic acid in mice with diabetes. Journal of biological chemistry, 2011: p. jbc. M110. 217216.

72. Amritha, C., P. KumArAvelu, and D.D. Chellathai, Evaluation of Anti Cancer Effects of DPP-4 Inhibitors in Colon Cancer-An Invitro Study. Journal of clinical and diagnostic research: JCDR, 2015. 9(12): p. FC14.

73. Vangoitsenhoven, R., C. Mathieu, and B. Van der Schueren, GLP1 and cancer: friend or foe? Endocrine-related cancer, 2012: p. ERC-12-0111.

74. Larrinaga, G., et al., Dipeptidyl-peptidase IV activity is correlated with colorectal cancer prognosis. PLoS One, 2015. 10(3): p. e0119436.

75. Li, X.-n., et al., Glucagon-like Peptide-1 Analogues Inhibit Proliferation and Increase Apoptosis of Human Prostate Cancer Cells in vitro. Experimental and Clinical Endocrinology \& Diabetes, 2017. 125(02): p. 91-97.

76. Cases, A.I., et al., Significance of expression of glucagon-like peptide 1 receptor in pancreatic cancer. Oncology reports, 2015. 34(4): p. 1717-1725.

77. Nomiyama, T., et al., Exendin-4, a glucagon-like peptide-1 receptor agonist, attenuates prostate cancer growth. Diabetes, 2014: p. DB_131169.

78. Lu, R., et al., Synergistic anti-tumor effects of liraglutide with metformin on pancreatic cancer cells. PloS one, 2018. 13(6): p. e0198938.

79. Kanda, R., et al., Expression of the glucagon-like peptide-1 receptor and its role in regulating autophagy in endometrial cancer. BMC cancer, 2018. 18(1): p. 657.

80. Koehler, J.A. and D.J. Drucker, Activation of glucagon-like peptide-1 receptor signaling does not modify the growth or apoptosis of human pancreatic cancer cells. Diabetes, 2006. 55(5): p. 1369-1379.

81. Wenjing, H., et al., Exendin-4 does not modify growth or apoptosis of human colon cancer cells. Endocrine research, 2017. 42(3): p. 209-218. 
Table 1; Main evidences about SGLT2 inhibition and apoptosis suppression

\begin{tabular}{|c|c|c|}
\hline $\begin{array}{c}\text { SGLT2 } \\
\text { inhibitor }\end{array}$ & Inhibitory Effects on Apoptosis & Ref. \\
\hline Dapagliflozin & $\begin{array}{l}\text { Prevented of obesity-induced apoptosis by attenuation } \\
\text { of oxidative stress, ER stress and obesity }\end{array}$ & $\begin{array}{l}\text { (Nipon } \\
\text { Chattipakorn, } \\
\text { 2018) }\end{array}$ \\
\hline Empagliflozin & $\begin{array}{r}\text { Inhibited beta cell apoptc } \\
\text { glucotox }\end{array}$ & $\begin{array}{l}\text { (Cheng et al., } \\
\text { 2016) }\end{array}$ \\
\hline Dapagliflozin & $\begin{array}{l}\text { Provide neuroprotective effects by preventing } \\
\text { oxidative stress induced apoptosis in brain }\end{array}$ & $\begin{array}{l}(\text { Sa- } \\
\text { nguanmoo et } \\
\text { al., 2017) }\end{array}$ \\
\hline Dapagliflozin & Reduces apoptotic processes in renal diabetic tissue & $\begin{array}{l}\text { (Shin et al., } \\
\text { 2016) }\end{array}$ \\
\hline Empagliflozin & $\begin{array}{c}\text { Protected renal proximal tubular cells from apoptosis } \\
\text { by correcting lipid metabolism and reducing intra-renal } \\
\text { lipotoxicity }\end{array}$ & $\begin{array}{l}\text { (Lee et al., } \\
\text { 2018) }\end{array}$ \\
\hline Dapagliflozin & $\begin{array}{r}\text { Inhibited apoptosis by attenuat } \\
\text { responses and oxidati }\end{array}$ & $\begin{array}{l}\text { (Terami et al. } \\
\quad, 2014)\end{array}$ \\
\hline Dapagliflozin & $\begin{array}{l}\text { Reduced oxidative stress dependent apoptosis in } \\
\text { diabetic kidneys of mice }\end{array}$ & $\begin{array}{l}\text { (Hatanaka et } \\
\text { al. , 2016) }\end{array}$ \\
\hline Luseogliflozin & $\begin{array}{c}\text { Preserved pancreatic beta cell mass by suppressing } \\
\text { apoptosis in diabetic mice }\end{array}$ & $\begin{array}{l}\text { (Okauchi et } \\
\text { al., 2016) }\end{array}$ \\
\hline Tofogliflozin & $\begin{array}{l}\text { Prevented of oxidative stress dependent apoptosis in } \\
\text { renal proximal tubules of human cultured proximal } \\
\text { tubular cells }\end{array}$ & $\begin{array}{l}\text { (Ishibashi et } \\
\text { al., 2016) }\end{array}$ \\
\hline $\begin{array}{l}\text { siRNAs against } \\
\text { SGLT2 }\end{array}$ & $\begin{array}{l}\text { Prevented of AGEs-induced apoptosis in proximal } \\
\text { tubular cells exposed to high glucose concentrations }\end{array}$ & $\begin{array}{l}\text { (Maeda et } \\
\text { al., 2013) }\end{array}$ \\
\hline Dapagliflozin & $\begin{array}{l}\text { Slows the progression of kidney tissue injuries by } \\
\text { suppressing apoptosis via attenuating oxidative stress } \\
\text { and inflammation in diabetic animals }\end{array}$ & $\begin{array}{l}\text { (Han et al., } \\
\text { 2018) }\end{array}$ \\
\hline
\end{tabular}

(AGE=advanced glycation end product, $\mathrm{ER}=$ endoplasmic reticulum, siRNA= small interfering RNA) 
Table 2; Main evidences on SGLT2 inhibition and apoptosis induction

\begin{tabular}{|c|c|c|}
\hline $\begin{array}{l}\text { SGLT2 } \\
\text { inhibitor }\end{array}$ & Stimulatory Effects on Apoptosis & Ref. \\
\hline Ipragliflozin & $\begin{array}{l}\text { Induces apoptosis in the breast cancer cells via } \\
\text { membrane hyperpolarization and mitochondrial } \\
\text { dysfunction }\end{array}$ & $\begin{array}{l}\text { (KOMATSU } \\
\text { et al., 2018) }\end{array}$ \\
\hline Dapagliflozin & $\begin{array}{l}\text { Increased the early and late cellular apoptosis in human } \\
\text { renal cancer cells }\end{array}$ & $\begin{array}{l}\text { (Kuang et } \\
\text { al., 2017) }\end{array}$ \\
\hline Canagliflozin & $\begin{array}{l}\text { Induces apoptotic processes in human hepatocellular } \\
\text { carcinoma cells }\end{array}$ & $\begin{array}{l}\text { (Kaji et al., } \\
\text { 2018) }\end{array}$ \\
\hline Exenatide & $\begin{array}{l}\text { Increases apoptosis by cAMP dependent mechanism in } \\
\text { murine colon cancer cells }\end{array}$ & $\begin{array}{l}\text { (Koehler et } \\
\text { al. , 2011) }\end{array}$ \\
\hline Phlorizin & $\begin{array}{l}\text { Stimulates apoptosis by up-regulating the BCL2, } \\
\text { activation of caspase-3, reduces ATP level and } \\
\text { mitochondrial membrane potential and arrest cell cycle } \\
\text { in human hepatocellular carcinoma HepG2 cells }\end{array}$ & $\begin{array}{c}\text { (Nair and } \\
\text { Rupasinghe, } \\
\text { 2014) }\end{array}$ \\
\hline
\end{tabular}

cAMP - cyclic adenosine monophosphate 
Table 3; Main evidences about effects of GLP-1RA \& DPP-4i on apoptosis process

\begin{tabular}{|c|c|c|}
\hline GLP-1RA \& DPP-4i & Inhibitory Effects on Apoptosis & Ref. \\
\hline GLP-1 peptide & $\begin{array}{l}\text { Inhibit beta cells' apoptosis by caspase-3 down- } \\
\text { regulation and the up-regulation of bcl- } 2\end{array}$ & $\begin{array}{l}\text { (Farilla et } \\
\text { al., 2003) }\end{array}$ \\
\hline Vildagliptin & $\begin{array}{l}\text { Attenuated neuronal apoptosis by improving } \\
\text { mitochondrial function and ameliorating } \\
\text { inflammation }\end{array}$ & $\begin{array}{l}\text { (Sa- } \\
\text { nguanmoo } \\
\text { et al., 2017) }\end{array}$ \\
\hline Extedinn-4 & $\begin{array}{l}\text { Reduces } \beta \text {-cells' apoptosis and induces islets' } \\
\text { neogenesis by attenuating inflammatory cytokines } \\
\text { as IL- } 1 \beta, \text { TNF- } \alpha \text {, and IF- } \gamma \text { in diabetic rats }\end{array}$ & $\begin{array}{l}\text { (Li et al., } \\
\text { 2003) }\end{array}$ \\
\hline Extedinn-4 & $\begin{array}{l}\text { Makes beneficial effects on } \beta \text {-cell survival and } \\
\text { function by increasing Akt signaling pathway, } \\
\text { SIRT1 and } \alpha \text {-Klotho up-regulation leading to } \\
\text { apoptosis suppression in human cultured islet cells }\end{array}$ & $\begin{array}{l}\text { (Son et al., } \\
\text { 2018) }\end{array}$ \\
\hline GLP-1 peptide & $\begin{array}{c}\text { Protect against apoptosis by improvement in } \\
\text { mitochondrial function and PKA and PI3K } \\
\text { signaling pathways }\end{array}$ & $\begin{array}{l}\text { (Chang et } \\
\text { al., 2016) }\end{array}$ \\
\hline Extedinn-4 & $\begin{array}{l}\text { Prevents inflammation-induced apoptosis by a PKB- } \\
\text { dependent mechanism }\end{array}$ & $\begin{array}{l}\text { (Li et al., } \\
2005)\end{array}$ \\
\hline GLP-1 peptide & $\begin{array}{c}\text { Prevents apoptosis by induction of IGF-1 receptor } \\
\text { expression and reducing inflammatory mediators } \\
\text { leading to cAMP activation and beta cells' } \\
\text { regeneration }\end{array}$ & $\begin{array}{l}\text { (Cornu et } \\
\text { al., 2008) }\end{array}$ \\
\hline GLP-1 peptide & $\begin{array}{l}\text { Protects cardiomyocytes by suppressing apoptosis } \\
\text { through PI3K and ERK1/2 dependent pathways }\end{array}$ & $\begin{array}{l}\text { (Ravassa et } \\
\text { al. , 2011) }\end{array}$ \\
\hline Diprotin A & $\begin{array}{l}\text { Inhibits apoptosis in endothelial cells by making } \\
\text { cytoprotective effects in human umbilical veins }\end{array}$ & $\begin{array}{l}\text { (Nagamine } \\
\text { et al., 2017) }\end{array}$ \\
\hline Desfluorositagliptin & $\begin{array}{c}\text { Prevents beta cells' apoptosis by down-regulating } \\
\text { proapoptotic agents in diabetic mice }\end{array}$ & $\begin{array}{l}\text { (Shirakawa } \\
\text { et al., 2011) }\end{array}$ \\
\hline
\end{tabular}

(IL-1 $\beta=$ interleukin-1 beta, IF- $\gamma$ =interferon-gamma, SIRT1= sirtuin-1, $\alpha$ Klotho=anti-aging protein, $\mathrm{PKB}=$ protein kinase $\mathrm{b}, \mathrm{IGF}-1=$ insulin like growth factor-1, PKA= protein kinase $\mathrm{a}, \mathrm{PI} 3 \mathrm{~K}=$ Phosphoinositide 3-kinase, ERK1= Mitogen-activated protein kinase 3) 
Table 4; Main evidences about GLP-1RA \& DPP-4i agents and apoptosis induction

\begin{tabular}{|c|c|c|}
\hline $\begin{array}{c}\text { GLP-1RA \& } \\
\text { DPP-4i }\end{array}$ & Stimulatory Effects on Apoptosis & Ref. \\
\hline Sitagliptin & $\begin{array}{c}\text { Increases apoptosis process in human cultured colon } \\
\text { cancer cells }\end{array}$ & $\begin{array}{c}\text { (Amritha et } \\
\text { al., 2015) }\end{array}$ \\
\hline DPP-4i & $\begin{array}{c}\text { DPP-4 upregulated in cancer cells due to positive effects } \\
\text { on apoptosis }\end{array}$ & $\begin{array}{c}\text { Larrinaga } \\
\text { et al., 2015) }\end{array}$ \\
\hline $\begin{array}{c}\text { Exenatide and } \\
\text { liraglutide }\end{array}$ & $\begin{array}{c}\text { Induce apoptosis by raising Bax/Bcl-2 ratio and } \\
\text { activating p38 molecular mechanisms in human prostate } \\
\text { cancer cells }\end{array}$ & $\begin{array}{c}\text { (Li et al., } \\
\text { 2017) }\end{array}$ \\
\hline $\begin{array}{c}\text { GLP-1R } \\
\text { expression }\end{array}$ & $\begin{array}{c}\text { Implicated in prostatic cancer progression and modulates } \\
\text { it by apoptosis induction }\end{array}$ & $\begin{array}{c}\text { (Cases et } \\
\text { al. , 2015) }\end{array}$ \\
\hline Exendin-4 & $\begin{array}{c}\text { Attenuates prostate cancer growth through apoptosis } \\
\text { induction via ERK-MAPK pathway inactivation }\end{array}$ & $\begin{array}{c}\text { (Nomiyama } \\
\text { et al. , } \\
\text { 2014) }\end{array}$ \\
\hline Liraglutide & $\begin{array}{c}\text { Attenuates tumor size by apoptosis induction via AMPK } \\
\text { signaling pathways }\end{array}$ & $\begin{array}{c}\text { (Lu et al. , } \\
\text { 2018) }\end{array}$ \\
\hline Liraglutide & $\begin{array}{c}\text { GLP-1R expression is correlated to higher survival in } \\
\text { human endometrial cancer cells }\end{array}$ & $\begin{array}{c}\text { (Kanda et } \\
\text { al. , 2018) }\end{array}$ \\
\hline
\end{tabular}

$(\mathrm{AMPK}=\mathrm{AMP}$-activated protein kinase) 
Figure 1; Main molecular mechanisms between diabetes mellitus and apoptosis and the possible modulatory roles of SGLT2i, GLP-RA and DPP-4i

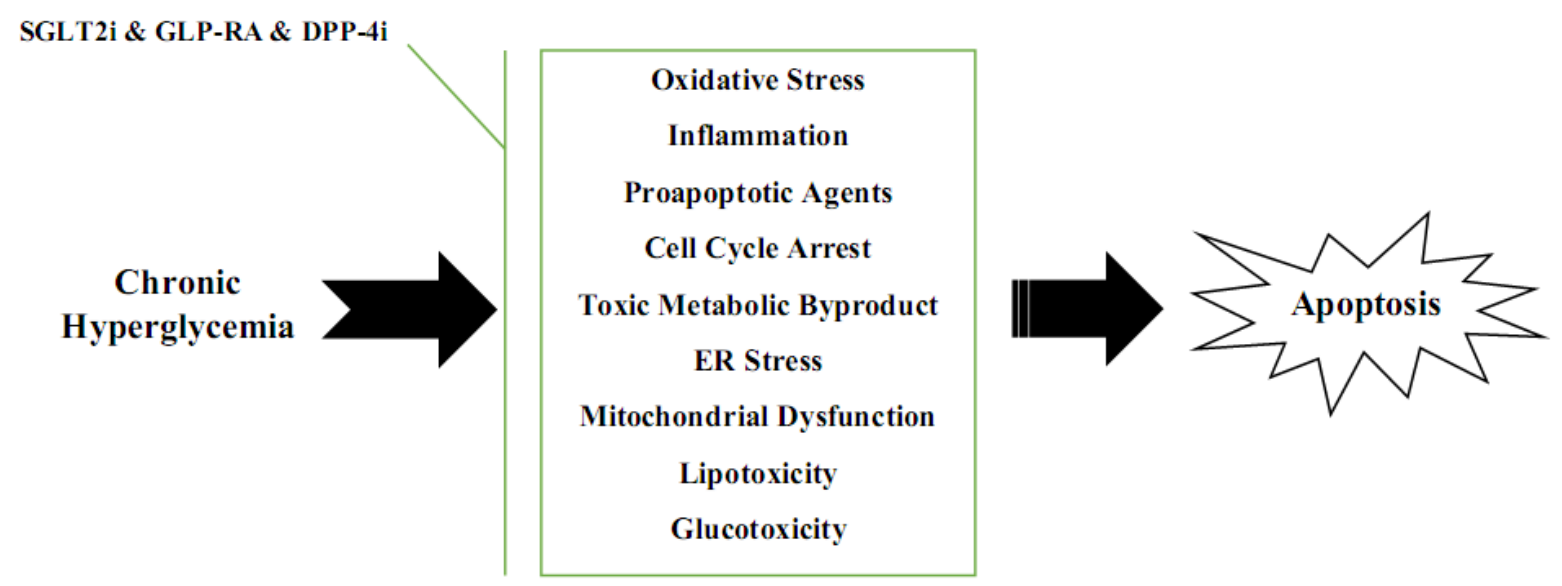


